\title{
Preparation of Multilayer Composites by Combination of Centrifugal Filter Pressing and Rate-Controlled Sintering
}

\author{
Osami ABE and Jun-ichi YAMADA ${ }^{\dagger}$ \\ Department of Materials Science, Faculty of Engineering, Ibaraki University, 4-12-1, Nakanarusawa, Hitachi-shi 316

\begin{abstract}
遠心フィルター成形法と速度制御焼結法を併用した積層複合材料の作製
阿部修実・山田純一十
\end{abstract} \\ 茨城大学工学部物質工学科, 316 日立市中成沢町 4-12-1
}

[Received February 16, 1994; Accepted May 19, 1994]

\begin{abstract}
Multilayer composites (MLCs) of alumina and yttriadoped tetragonal zirconia (YTZ) with the layer thickness of 50-200 $\mu \mathrm{m}$ have been fabricated. A combination of centrifugal filter-pressing and rate-controlled sinter" ing has been proposed for preparing MLCs with a strengthened layer interface. Centrifugal-pressing was efficiently used to strengthen the layer interface by introducing the compositional gradient. Rate-controlled sintering reduced interlayer stress generation during sintering, prevented delamination and contributed to the strengthening of the interface. It was considered that the strengthened layer interface contributed to the toughening of MLCs by means of (1) effective crack deflection in the alumina layers, (2) enhanced transformation toughening due to a deformed frontal zone shape in the YTZ layer constrained between the alumina layers, and possibly (3) crack pinning at the layer interface.
\end{abstract}

Key-words : Multilayer composites, YTZ, Alumina, Centrifugal filter pressing, Rate-controlled sintering

\section{Introduction}

Improvement of fracture toughness is important for the application of engineering ceramics. One approach to toughening is dispersion reinforcement using whiskers, ${ }^{1,2)}$ particles, ${ }^{3)}$ and platelets ${ }^{4)-6)}$ in expectation of deflection, pinning, and pull-out effects. However, the improvement is not very dramatic in these mechanisms due to the short-range deflection of crack propagation paths. High fracture toughness is efficiently attained by long-fiber reinforcement ${ }^{7)-9}$ ) causing wide-range deflection, but the low sintered density results in the problem of low corrosion resistance. ${ }^{9)}$ The reduced reliability or reproducibility of the mechanical properties caused by the structural inhomogeneity is another problem. The widerange "ordered inhomogeneity" or "controlled inhomogeneity" providing high fracture toughness should be intelligently introduced into the micro-

Present address : Mitsubishi Gas Chemical, Company, Inc., 3500, Hamamatsu-cho, Niigata-shi 950-31

現在 : 三菱ガス化学(株)新潟工業所, 950-31 新潟市浜松町 3500 structure without severely disturbing the sinterabiliy. From this point of view, attention to layered composites ${ }^{10)-17)}$ as well as dual-structure composites ${ }^{10,18), 19)}$ and nanocomposites ${ }^{10), 20), 21)}$ has arisen in new approaches for toughening, in contrast to the above-mentioned "traditional composites".

Three toughening mechanisms have been proposed for the layered composites : (1) enhanced transformation toughening of Ce-doped $\mathrm{ZrO}_{2}$ for multilayer Ce-TZP $/ 50 \% \mathrm{Al}_{2} \mathrm{O}_{3}+50 \%$ Ce-TZP composites, ${ }^{11,12)}$ (2) compressive stress in the outer layers for trilayer composites, ${ }^{14)-16)}$ and (3) crack deflection along the joined interface. ${ }^{17)} \mathrm{A}$ strongly joined layer interface is the most important feature to realize mechanisms (1) and (2) efficiently. However, as described by Marshall and co-workers, ${ }^{11), 12)}$ the mismatch of shrinkage (and perhaps shrinkage rate) between the constituents sometimes causes cracking in layers and layer interfaces during sintering. They minimized the mismatch by using a mixed composition $\left(50 / 50 \mathrm{vol} \% \mathrm{Al}_{2} \mathrm{O}_{3} / \mathrm{Ce}-\mathrm{ZrO}_{2}\right)$ instead of pure $\mathrm{Al}_{2} \mathrm{O}_{3}$.

In the present work, multilayer composites (MLCs) of pure $\mathrm{Al}_{2} \mathrm{O}_{3}$ and YTZ (yttria-partiallystabilized tetragonal zirconia) have been prepared by a combination of centrifugal filter-pressing (CFP) and rate-controlled sintering (RCS). RCS 22)-25) was adopted to minimize the mismatch of shrinkage rate and realize the use of pure $\mathrm{Al}_{2} \mathrm{O}_{3}$ as one of the constituents. The reduced mismatch of shrinkage rate during RCS should contribute to the strengthening of the layer interface. Furthermore, in the present study, a compositional gradient was introduced at the interface for strengthening. It is expected that the gradient will result in a microstructure similar to those of $\mathrm{Al}_{2} \mathrm{O}_{3}$-dispersed $\mathrm{YTZ}$ and YTZ-dispersed $\mathrm{Al}_{2} \mathrm{O}_{3}$ at the interface. It is known that both particle-dispersed materials have higher strength and toughness than those of their monoliths. ${ }^{26)-28)}$ The strengthened layer interface should contribute to toughening by means of crack pinning at the interface, enhanced transformation toughening by the spreading transformation zone along the region adjacent to the layer, and effective 
crack deflection along the layers due to the residual stress induced during cooling by thermal expansion mismatch $\left(9.6 \times 10^{-6} \mathrm{~K}^{-1}\right.$ for $\mathrm{Al}_{2} \mathrm{O}_{3},{ }^{29)} 13.1 \times 10^{-6}$ $\mathrm{K}^{-1}$ for $\left.\mathrm{YTZ}^{30)}\right)$.

\section{Experimental}

Alumina (Taimei Chemicals, $15 \mathrm{~m}^{2} \cdot \mathrm{g}^{-1}$ ) and YTZ (Hokko Chemicals, $\mathrm{Y}_{2} \mathrm{O}_{3}: 5 \mathrm{~mol} \%, 15 \mathrm{~m}^{2} \cdot \mathrm{g}^{-1}$ ) powders were used as suspensions in water. Weighed powders were ball-milled $(40 \mathrm{~h})$ in water for dispersion without dispersants. CFP was carried out with the use of the equipment illustrated in Fig. 1. The centrifugal vessel was a double-wall container. A Cellulose nitrate filter $(\phi 25$, pore size : $0.2 \mu \mathrm{m})$ was placed on the porous mount (Nikko Co., Ltd., Phenol resin, pore size : $10-15 \mu \mathrm{m})$ at the bottom of the inner tube. Alumina and YTZ suspensions (20 $\mathrm{cm}^{3}$ ) were alternately fed into the inner tube. The typical acceleration and treatment time for CFP were $1.48 \times 10^{4} \mathrm{~m} \cdot \mathrm{s}^{-2}$ (rotation : $3000 \mathrm{rpm}$ ) and 60 min, respectively. The thickness of layers was controlled by adjusting the powder content of the suspensions : $0.5,0.25$, and $0.125 \mathrm{vol} \%$ for 200,100 , and $50 \mu \mathrm{m}$ thickness, respectively. The compositional gradient of the layer interface was introduced by feeding the suspension $\left(1 \mathrm{~cm}^{3}\right)$ containing both $\mathrm{Al}_{2} \mathrm{O}_{3}$ and YTZ powders $(0.05+0.05 \mathrm{vol} \%)$. After $\mathrm{CFP}$, aqueous solution of Polyvinylalcohol (2 wt\%) was passed through the green body and bound the powder particles to prevent cracking during drying. The green body was dried carefully, cut into rectangular bars $(5 \times 4 \times 20 \mathrm{~mm})$, cold-isostatically pressed (CIP-ed) at $200 \mathrm{MPa}$, and dewaxed at $700^{\circ} \mathrm{C}$ in air. Three kinds of MLC green bodies were prepared by this procedure: MLC21, MLC41 and MLC79, where the numbers indicate the total number of layers. The individual layer thickness was in the order of MLC21>MLC41>MLC79, with the same overall thickness $(4 \mathrm{~mm})$.

Sintering was conducted by two methods : conventional temperature-controlled sintering (TCS, heat-

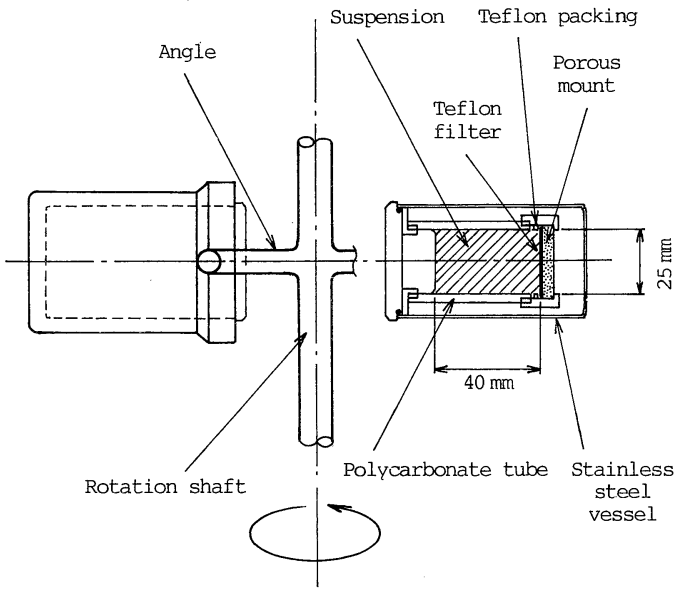

Fig. 1. Schematic representation of the equipment for centrifugal filter pressing. ing rate $: 5 \mathrm{~K} \cdot \mathrm{min}^{-1}$ ) and $\mathrm{RCS}$ (Rigaku-Denki, DRC-2) where the shrinkage rates in parallel or normal to the layer were controlled at $0.1 \% \cdot \mathrm{min}^{-1}$. The sintered density was measured by the Archimedes method. The sintered materials were ground and polished (\#3000) for microstructural observation (SEM; JEOL, JSM-5200). The Vickers indentation test (Akashi, AVK-HF, $20 \mathrm{~kg}$ ) was performed to observe the crack propagation.

\section{Results and discussion}

Figure 2 shows the height $(h)$ of the residual suspension of $0.5 \mathrm{vol} \% \mathrm{Al}_{2} \mathrm{O}_{3}$ powder compared with the height calculated from Stokes Eq. (1):

$$
h=\frac{d^{2}\left(\rho_{\mathrm{p}}-\rho_{\mathrm{m}}\right) a}{18 \eta} t
$$

In Eq. (1), $d$ is the particle diameter, $\rho_{\mathrm{p}}$ the density of particles, $\rho_{\mathrm{m}}$ the density of liquid medium, $a$ the centrifugal acceleration, $t$ the time of centrifugation, and $\eta$ the viscosity of liquid. Equation (1) shows that $36.2 \mathrm{~min}$ is required for the complete sedimentation of $0.1 \mu \mathrm{m} \mathrm{Al}_{2} \mathrm{O}_{3}$ (BET-equivalent particle size) in 20 $\mathrm{cm}^{3}$ suspension $(h=40.7 \mathrm{~mm})$. Distilled water containing no powder particles passed through the filter within $30 \mathrm{~s}$. The first layer $(n=1)$ could be filtered within 2 min, which was a sufficiently short time to form a layer with little influence of size separation. When the operation progressed to 20 layers $(n=20)$, the time required to form one layer increased to 20 min, leading to increased influence of size separation. However, the suspension was filtered in a time shorter than 36.2 min which was necessary for Stokes sedimentation. The filtering rate should be shortened by continuously feeding the suspension and maintaining a constant $h$, because the centrifugal force increases proportionally with the weight of suspension. The green density after CIPing ranged from 51.7 to $52.3 \%$ of the theoretical value.

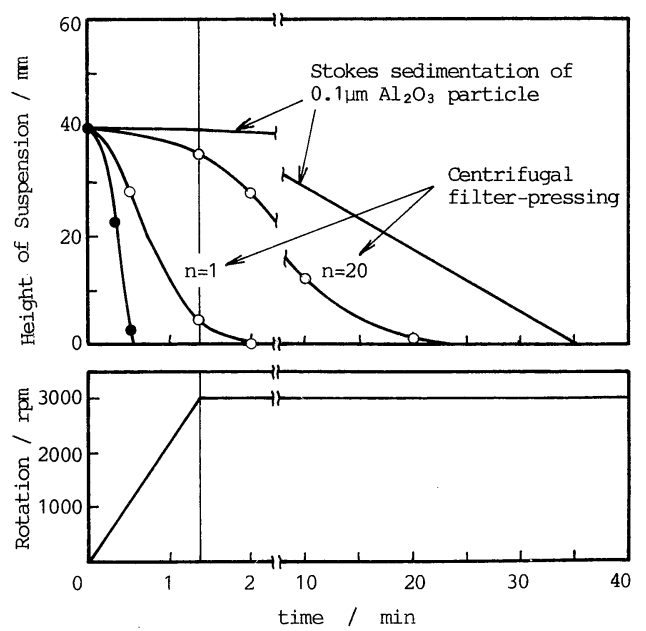

Fig. 2. Rate of centrifugal filter-pressing comparing with Stokes sedimentation of $\mathrm{Al}_{2} \mathrm{O}_{3}$ powder; powder content in suspension : $0.5 \mathrm{vol} \%$ (thickness of one layer : $200 \mu \mathrm{m}$ ). 
Figure 3 shows the temperature dependence of shrinkage rate (time differential of shrinkage) in the parallel and normal directions to the layer for TCS of MLC21, where the average shrinkage rate was obtained using Eq. (2).

$$
\begin{aligned}
& \text { (average shrinkage rate) } \\
& \quad=3 \sqrt{(\text { parallel }) \times(\text { normal })^{2}}
\end{aligned}
$$

The normal shrinkage was predominant at the initial stage of densification below $1370^{\circ} \mathrm{C}$, parallel in $1370-$ $1480^{\circ} \mathrm{C}$, and normal again at the final stage above $1480^{\circ} \mathrm{C}$. It is considered that the poor sinterability of the layer interface having particle dispersion struc-
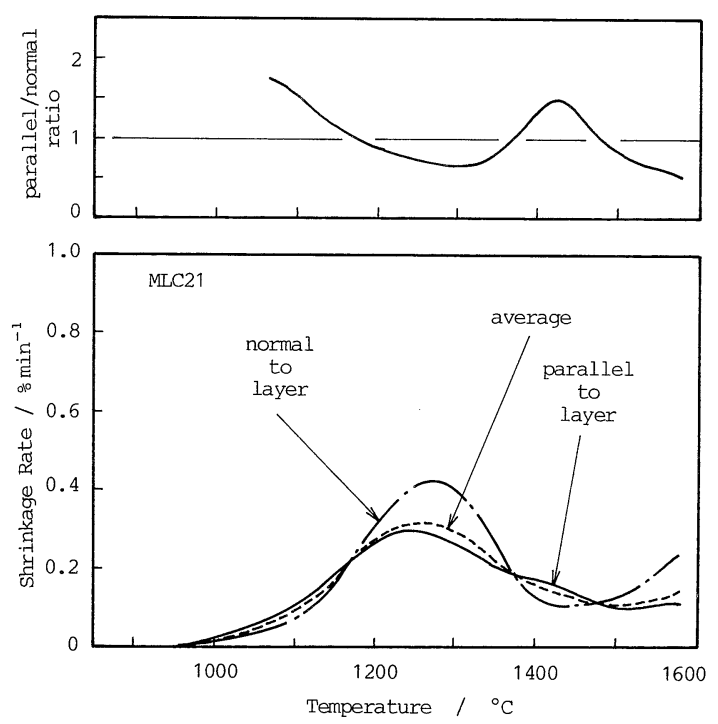

Fig. 3. Temperature dependence of shrinkage rate in parallel and normal directions of layer for TCS of MLC21; heating rate : 5 $\mathrm{K} \cdot \mathrm{min}^{-1}$.
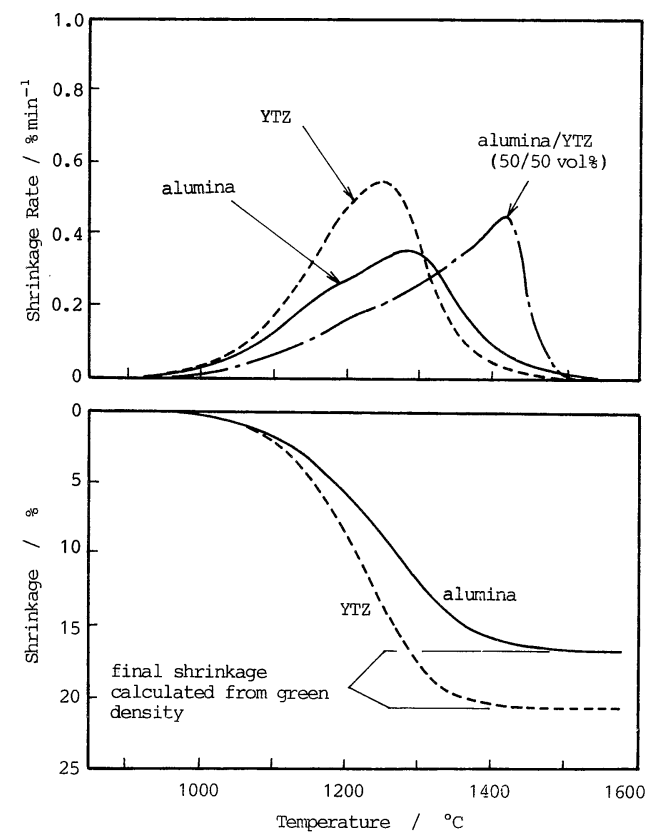

Fig. 4. Temperature dependence of shrinkage and shrinkage rate of $\mathrm{Al}_{2} \mathrm{O}_{3}$, YTZ, and a mixture of $\mathrm{Al}_{2} \mathrm{O}_{3}$ and $\mathrm{YTZ}$ (50:50 $\mathrm{vol} \%$ ); heating rate $: 5 \mathrm{~K} \cdot \mathrm{min}^{-1}$. ture retarded parallel shrinkage rather than the normal one in the initial stage. As shown in Fig. 4, the mixed powder of $\mathrm{Al}_{2} \mathrm{O}_{3}$ and $\mathrm{YTZ}$ (50/50 mol\%) indicated poor sinterability in the temperature range corresponding to the initial stage (below $1330^{\circ} \mathrm{C}$ ). Inside the layer, the driving force for materials transport would be inefficiently exploited for parallel shrinkage since both sides were confined by the poorly sinterable composition, whereas it is not disturbed in the normal direction without the confinement. After a certain progress in the first-stage densification, even the potential for normal shrinkage decreased and the normal shrinkage rate decreased. However, the increase of temperature activated the densification of inter layer composition, resulting in the increase of the parallel shrinkage rate in the second stage above $1370^{\circ} \mathrm{C}$. This was supported by the fact that the peak temperature of the shrinkage rate for $\mathrm{Al}_{2} \mathrm{O}_{3} / \mathrm{YTZ}^{\prime}$ mixture in Fig. $4\left(1400^{\circ} \mathrm{C}\right)$ agreed with the temperature for the second peak of parallel shrinkage in Fig. 3.

Figures 5 and 6 show the temperature dependence of shrinkage rate during TCS of MLC41 and MLC79. For MLC41, the transition temperature from the first to second stage was $1360^{\circ} \mathrm{C}$, which was almost the same as that for MLC21. However, for MLC79, the transition temperature decreased markedly to $1280^{\circ} \mathrm{C}$. This was due to the increase in the parallel shrinkage rate, as shown in Fig. 6. The increase of the number of layer interfaces having poor sinterability (41 layers for MLC41 to 79 layers for MLC79) promoted parallel shrinkage. The reason for this apparently inconsistent behavior is not evident, but high sintered density was obtained for MLC79, as indicated in Table 1, after sintering at $1500^{\circ} \mathrm{C}$ for $60 \mathrm{~min}$. Table 1 also indicates the ratios of normal to parallel shrinkage after sintering. The ratio was largest for MLC41 and decreased for MLC21 and MLC79. The decrease for MLC21 is due
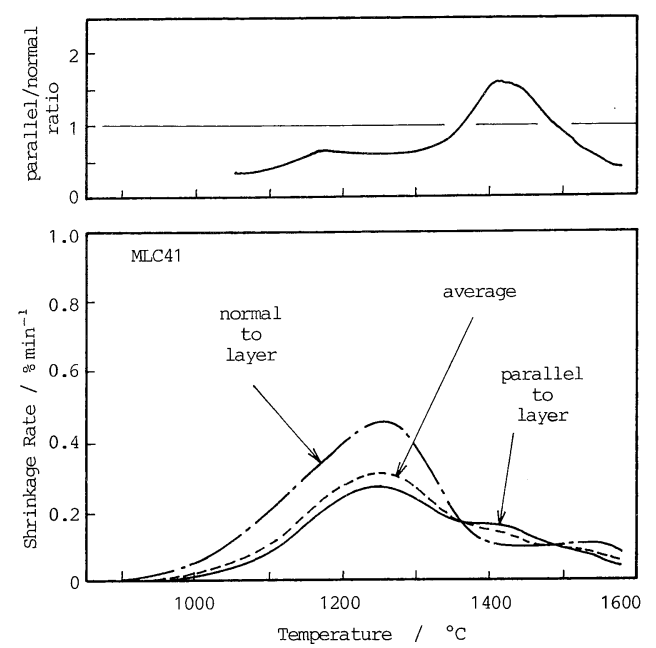

Fig. 5. Temperature dependence of shrinkage rate in parallel and normal directions of layer for TCS of MLC41; heating rate : 5 $\mathrm{K} \cdot \min ^{-1}$. 

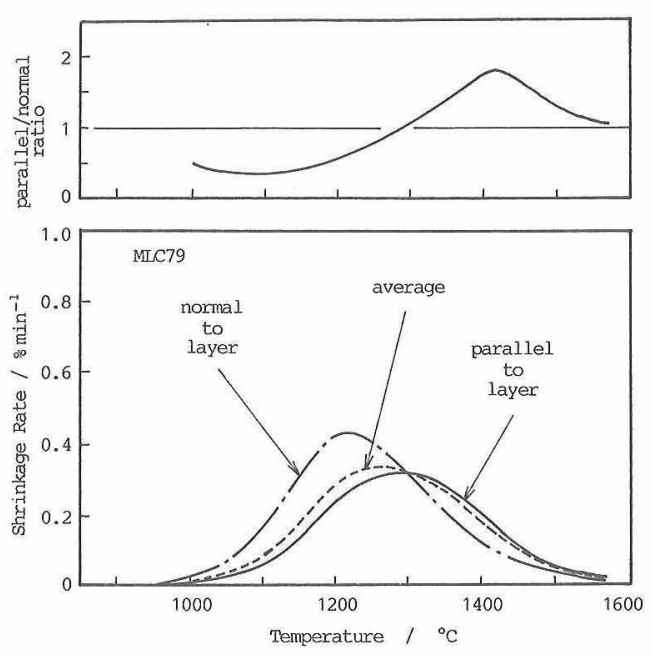

Fig. 6. Temperature dependence of shrinkage rate in parallel and normal directions of layer for TCS of MLC79; heating rate : 5 $\mathrm{K} \cdot \mathrm{min}^{-1}$.

Table 1. Sintered Density and Anisotropy of Shrinkage After TCS and $\operatorname{RCS}\left(1500^{\circ} \mathrm{C}, 60 \mathrm{~min}\right)$.

\begin{tabular}{|c|c|c|c|c|c|}
\hline & \multicolumn{3}{|c|}{ Relative density (\%) } & \multicolumn{2}{|c|}{$\begin{array}{l}\text { Ratio of normal to } \\
\text { parallel shrinkage }\end{array}$} \\
\hline & TCS & & & TCS & RCS \\
\hline ZA21 & 88.9 & & & 1.16 & - \\
\hline ZA41 & 92.2 & - & $95.3_{\mathrm{h}}^{\mathrm{b}}$ & 1.54 & $-1.47^{b}$ \\
\hline ZA79 & 95.3 & $95.9^{\mathrm{a}}$ & $97.0^{\mathrm{b}}$ & 1.27 & $1.22^{\mathrm{a}} 1.21^{\mathrm{b}}$ \\
\hline
\end{tabular}

to the low sintered density, but the decrease for MLC79 should be correlated to the promoted shrinkage rate in the parallel direction.

Despite the high sintered density for MLC79, there is the possibility that the mismatch of the shrinkage rate between the normal and parallel directions induces stress at the layer interface and reduces the binding strength between layers. The reduction of the mismatch is expected for RCS where the shrinkage rate is controlled to relatively low values. Figure 7 shows the profiles of temperature and heating rate when the shrinkage rates in parallel $(\mathrm{P})$ and normal $(\mathrm{N})$ directions were controlled at $0.1 \% \cdot \mathrm{min}^{-1}$ for MLC79. The heating rate was limited within relatively low values at 1150 $1300^{\circ} \mathrm{C}$ where the normal shrinkage was predominant over the parallel one in TCS. The sintered densities for MLC41 and MLC79 were increased by RCS (Table 1). The effect of RCS in increasing the sintered density was evident for MLC41 which indicated severe mismatch of the temperature-dependent shrinkage rate between the normal and parallel directions during TCS. normal/parallel ratio of shrinkage in Table 1 was also reduced by RCS. This should be caused by the reduction of the mismatch of the shrinkage rates.

Figure 8 shows the microstructure of MLC41 and MLC79 after TCS and RCS (final heat-treatment


Fig. 7. Profiles of temperature, shrinkage rate, and corresponding heating rate during RCS of MLC79; P : parallel shrinkage rate was controlled, $\mathrm{N}$ : normal shrinkage rate was controlled.


Fig. 8. Influence of sintering method (TCS and RCS) on microstructure for MLC41 and MLC79; a : MLC41 (TCS), b : MLC41 (RCS), c : MLC79 (TCS), d : MLC79 (RCS), bar $=100 \mu \mathrm{m}, \mathrm{A}$ : $\mathrm{Al}_{2} \mathrm{O}_{3}$ layer, $\mathrm{Z}$ : $\mathrm{YTZ}$ layer.

condition : $1500^{\circ} \mathrm{C}, 60 \mathrm{~min}$ ). The dark and bright layers were the $\mathrm{Al}_{2} \mathrm{O}_{3}(\mathrm{~A})$ and $\mathrm{YTZ}(\mathrm{Z})$ layers, respectively. The layer thicknesses were $60-130 \mu \mathrm{m}$ (MLC41-TCS), 90-100 $\mu \mathrm{m}$ (MLC41-RCS), 20-50 $\mu \mathrm{m}$ (MLC79-TCS), and 25-50 $\mu \mathrm{m}$ (MLC79-RCS), respectively. They were almost equal to the intended values. The $\mathrm{Al}_{2} \mathrm{O}_{3}$ and $\mathrm{YTZ}$ layers were not delaminated and had very few inter layer cracks. The formation of $\mathrm{Y}^{\prime} \mathrm{TZ}$ and pure $\mathrm{Al}_{2} \mathrm{O}_{3}$ without delamination 
suggested that stress relaxation between the layers was achieved through the processes proposed in the present paper, i.e., the CFP including the composition-gradient layer interface and RCS. However, the MLC41-TCS sintered body (Fig. 8(a)) having the lowest density $(92.2 \%)$ contained many pores located in the top and bottom regions of the alumina layer and the central part of the YTZ layer despite the lack of cracks and pores at the layer interface. It was considered that the formation of these pores was related to the mismatch of shrinkage behaviors in the parallel and normal directions, as shown in Fig. 5. In the MLC41-RCS material, such pore formation was not observed and higher sintered density was obtained. Therefore, the reduction of the mismatch in shrinkage rates between the constituents is suggested to contribute to the improved microstructure in the RCS materials.

The cracks propagating from the Vickers indentation are shown in Fig. 8. In the YTZ layers, cracks did not propagate straight from the indentation but strayed, as indicated by the arrows in Figs. 8(b) and (c). Although most cracks were straight along the $\mathrm{Al}_{2} \mathrm{O}_{3}$ layers (arrows in Fig. 8(d)), they were observed within the layer and the layer interface did not include any cracks. Figure 9 shows the crack propagation from the indentation near the layer interface (a) and the microstructure around the layer interface (b) for MLC41-RCS. A compositiongradient boundary with the thickness of about 1.5 $\mu \mathrm{m}$ was observed at the layer interface in Fig. 9 (b). This thickness value was consistent with the $2 \mu \mathrm{m}$ estimated by comparing the volume and powder con-
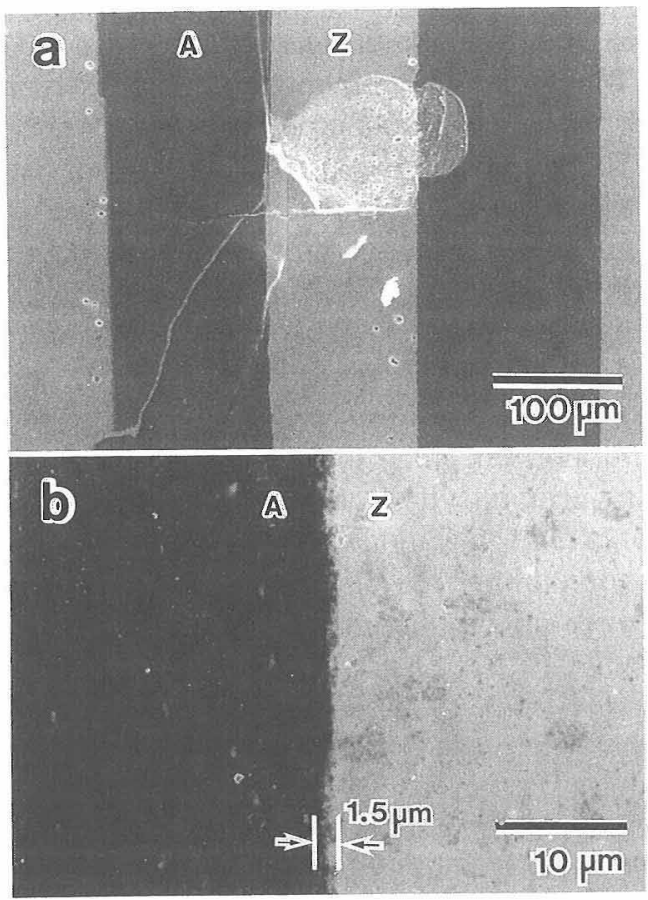

Fig. 9. Cracks formed after Vickers hardness test in MLC41$\mathrm{RCS}$ (a) and the layer interface (b); $\mathrm{A}: \mathrm{Al}_{2} \mathrm{O}_{3}$ layer, $\mathrm{Z}$ : $\mathrm{YTZ}$ layer. tent of suspensions for the composition-gradient layer-boundary ( $1 \mathrm{~cm}^{3}$ suspension, $0.05+0.05 \mathrm{vol} \%$ $\mathrm{Al}_{2} \mathrm{O}_{3}+\mathrm{YTZ}$ powders) to those for $100 \mu \mathrm{m}$ layer thickness ( $20 \mathrm{~cm}^{3}$ suspension, 0.25 vol\% powder). The crack was effectively deflected in the $\mathrm{Al}_{2} \mathrm{O}_{3}$ layer, and peel-out of the YTZ layer was observed. It was considered that peel-out was caused by the volume increase due to the stress-induced transformation of YTZ. Peel-out in Fig. 9 was not of spherical shape elongated toward the direction of crack propagation but showed a shape spreading in the area constrained between $\mathrm{Al}_{2} \mathrm{O}_{3}$ layers. The lateral expansion of the zone shape means the increase of compressive stress at the crack tip, i.e., emphasized transformation toughening.

In Fig. 9 (a), another peel-out was observed in the $\mathrm{Al}_{2} \mathrm{O}_{3}$ layer. The second peel-out was probably induced as a result of the volume increase of adjacent YTZ. However, the second peel-out was discontinuous from the initial one at the layer interface. This strongly suggested that peel-out of YTZ terminated at the interface and a second peel-out started after further increase in volume of transformed YTZ. The pinning of cracks at the layer interface was not strongly evident, but the cracks in Fig. 9(a) propagated away from the layer interface although the defect at the interface should attract some cracks. It is considered that the deflection and peel-out were a result of strengthening of the layer interface. Therefore in these MLCs, the multitoughening including enhanced transformation toughening in YTZ layers, effective deflection in $\mathrm{Al}_{2} \mathrm{O}_{3}$ layers, and perhaps pinning at the layer interface was expected.

Figure 10 shows the microstructure inside the $\mathrm{Al}_{2} \mathrm{O}_{3}$ and YTZ layers of MLC41-RCS. The grain size was $0.5-2 \mu \mathrm{m}$ and $0.1-0.5 \mu \mathrm{m}$ for $\mathrm{Al}_{2} \mathrm{O}_{3}$ and YTZ, respectively. When comparing these values with the particle size of the starting powders $(0.1$ $\mu \mathrm{m}$ for $\mathrm{Al}_{2} \mathrm{O}_{3}$ and $0.07 \mu \mathrm{m}$ for $\mathrm{YTZ}$ ) estimated from the specific surface area, grain growth was considerable for $\mathrm{Al}_{2} \mathrm{O}_{3}$ rather than YTZ. However, the grain size was almost equal to that of their monolithic materials sintered at the same temperature and soaking time, indicating little influence of the layered structure and related change in shrinkage behavior on grain growth in layers. At the layer interface, the

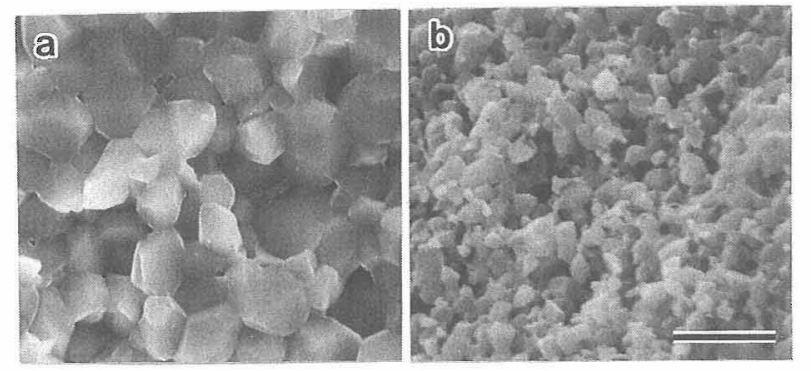

Fig. 10. Microstructure of $\mathrm{Al}_{2} \mathrm{O}_{3}$ (a) and $\mathrm{YTZ}$ (b) in the layers of MLC41-RCS; bar $=2 \mu \mathrm{m}$. 
grain size of $\mathrm{Al}_{2} \mathrm{O}_{3}$ and $\mathrm{YTZ}$ was reduced, as in most particle-dispersion ceramic composites. ${ }^{31}$ )

\section{Conclusion}

Multilayer composites (MLCs) of $\mathrm{Al}_{2} \mathrm{O}_{3}$ and yttria-doped zirconia (YTZ) with the layer thickness of 50-200 $\mu \mathrm{m}$ have been fabricated. In the MLCs, the toughening can be achieved by means of (1) effective crack deflection in the $\mathrm{Al}_{2} \mathrm{O}_{3}$ layer, (2) enhanced transformation toughening due to the deformed process zone kept inside the YTZ layer, and perhaps (3) crack pinning at the layer interface. A combination of centrifugal filter pressing and rate-controlled sintering has been proposed for preparing MLC with strengthened layer interface. Centrifugal filter-pressing was effectively used to strengthen the layer interface by introducing a compositional gradient. Ratecontrolled sintering reduced inter layer stress generation during sintering, prevented delamination and contributed to boundary strengthening. RCS also realized the lamination of $\mathrm{YTZ}$ with pure $\mathrm{Al}_{2} \mathrm{O}_{3}$, instead of $\mathrm{YTZ}$ with the mixture of $\mathrm{Al}_{2} \mathrm{O}_{3}$ and $\mathrm{ZrO}_{2}$, because of the reduced mismatch of the shrinkage behavior of the constituents during the RCS. The observation of the microstructure and indentation cracks strongly suggested that the strengthened layer interface contributed to multitoughening of MLCs.

\section{References}

1) Y. Goto and A. Tsuge, J. Am. Ceram. Soc., 76, 1420-24 (1993).

2) S. M. Smith, J. P. Singh and R. O. Scattergood, J. Am. Ceram. Soc., 76, 497-502 (1993).

3) T. Tani and S. Wada, Seramikkusu Ronbunshi, 97, 1195-98 (1989).

4) P. F. Becker, C. H. Hsueh, P. Angelini and T. N. Tiegs, J. Am. Ceram. Soc., 71, 1050-61 (1988).

5) G. H. Camplell, M. Rühle, B. J. Dalgleish and A. G. Evans, J. Am. Ceram. Soc., 73, 521-30 (1990).

6) Y. Chou and D. J. Green, J. Am. Ceram. Soc., 76, 1985-92 (1993).
7) M. Sakai, Seramikkusu Ronbunshi, 99, 983-92 (1991)

8) Y. Akimune, T. Ogasawara, N. Hirosaki and K. Yoneda, Seramikkusu Ronbunshi, 99, 180-82 (1991).

9) R. T. Bhatt, J. Am. Ceram. Soc., 75, 406-12 (1992).

10) M. P. Harmer, H. M. Chan and G. A. Miller, J. Am. Ceram. Soc., 75, 1715-28 (1992).

11) D. B. Marshall, J. J. Ratto and F. F. Lange, J. Am. Ceram. Soc., 74, 2979-87 (1991).

12) D. B. Marshall, Am. Ceram. Soc. Bull., 71, 969-73 (1992).

13) P. Sarkar, X. Haung and P. S. Nicholson, J. Am. Ceram. Soc., 75, 2907-09 (1992).

14) R. A. Cutler, J. D. Bright, A. V. Virker and D. K. Shetty, J. Am. Ceram. Soc., 70, 714-18 (1987).

15) A. V. Virker, J. F. Jue, J. J. Hansen and R. A. Cutler, J. Am. Ceram. Soc., 71, C148-51 (1988).

16) R. Sathyamoorthy, A. V. Virker and R. A. Cutler, J. Am. Ceram. Soc., 75, 1136-41 (1992).

17) H. Katsuki, H. Ichinose, A. Shiraishi, H. Takagi and Y. Hirata, J. Ceram. Soc. Japan, 101, 1068-70 (1993).

18) D. R. Clarke, J. Am. Ceram. Soc., 75, 739-58 (1993).

19) J. D. French, H. M. Chan, M. P. Harmer and G. A. Miller, J. Am. Ceram. Soc., 75, 418-23 (1993).

20) K. Niihara, Seramikkusu Ronbunshi, 99, 974-82 (1991).

21) J. Zhao, L. C. Trearns, M. P. Harmer, H. M. Chan, G. A. Miller and R. F. Cook, J. Am. Ceram. Soc., 76, 503-10 (1993).

22) H. Palmour, III and D. R. Johnson, Am. Ceram. Soc. Bull., 49, 767 (1970).

23) M. L. Huckabee and H. Palmour, III, Am. Ceram. Soc. Bull., 51, 574-76 (1972)

24) O. Abe, Seramikkusu Ronbunshi, 98, 591-96 (1990).

25) O. Abe, J. Ceram. Soc. Japan, 100, 1196-99 (1992).

26) X. Huang and P. S. Nicholson, J. Am. Ceram. Soc., 76, 1294-302 (1993)

27) C. Yu, D. K. Shetty, M. C. Shaw and D. B. Marshall, J. Am. Ceram. Soc., 75, 2991-94 (1992).

28) P. F. Becker, K. B. Alexander, A. Bleier, S. B. Waters and W. H. Warwick, J. Am. Ceram. Soc., 76, 657-63 (1993).

29) "Engineering Property Data on Selected Ceramics, Vol. III", Metals and Ceramics Information Center, Columbus, Ohio (1981) pp. 5. 4. 1-7.

30) "Engineering Property Data on Selected Ceramics, Vol. III", Metals and Ceramics Information Center, Columbus, Ohio (1981) pp. 5. 4. 5-7.

31) L. A. Xue, K. Meyer and I. Chen, J. Am. Ceram. Soc., 75, 822-29 (1992). 